\title{
Research on the Interactive Development of Strategic Emerging Industries and Traditional Industries in Shandong
}

\author{
Xu Jian, Gu Chao \\ School of Dongfang College, Shandong University of Finance and Economics, Tai'an, Shandong 271000, \\ China \\ axujiansd@126.com
}

Keywords: strategic emerging industries; traditional industries; interactive development

\begin{abstract}
At present, China is in the critical stage of economic transformation, and the continuous integration and development of traditional industries and emerging industries presents a new trend of development. In particular, the manufacturing industry has begun to increase the service properties, which improves the competition rate greatly, and the impact of Internet, electronic commerce and other technologies diversifies the development of traditional industries. Based on this, this paper, taking Shandong Province as an example, first analyzes the content of the interactive development of strategic emerging industries and traditional industries, then studies the development status of the strategic emerging industries and traditional industries in Shandong Province, and finally discusses the strategies of the interactive development between the strategic emerging industries and the traditional industries in Shandong Province. The research on the interactive development of emerging industries and traditional industries will provide some references.
\end{abstract}

\section{Introduction}

The development of traditional industries in China has been the main force of economic structure after a long period of accumulation. But after the financial crisis, the emerging industries have become the key content of the economic development. Therefore, under the current social situation, the emerging industries need to be effectively combined with the traditional industries to stimulate the potential of economic development, which can provide impetus to the progress of the society and let the economy be made. Development is more responsive to the needs of the society. The traditional industries in Shandong mainly include building materials, machinery, chemical, metallurgical, light industry and textile, which account for more than $70 \%$ of the total industry in the province. However, in the process of development, the quality of the products is not high and the related technologies are relatively backward. The economic development often requires a large amount of energy and even the environment. It also has a certain influence. Therefore, under the current trend of social development, it is necessary to integrate the strategic new industry with the traditional industry effectively, optimize the traditional industry and carry out strategic layout and development to the new industry at the same time, so as to optimize the industrial layout of the whole Shandong Province and provide strong economic development. The support of the force.

\section{Contents of Interactive Development between Strategic Emerging Industries and Traditional Industries}

The interactive development of strategic emerging industries and traditional industries in Shandong mainly includes three aspects, which are embodied as follows:

(1) The interactive development of industrial elements. The new materials and energy products in Shandong are an effective substitute for the traditional industry. Through the research and development of new materials and energy products, it can reduce the pollution to the environment, and can also improve the utilization of energy, and also help to reduce the cost. Especially in the 
current environment, the industry of energy environmental protection and information technology in Shandong is continuously optimizing and upgrading, which provides effective help to the machinery product processing and equipment upgrading of the iron and steel industry. Therefore, in the process of subsequent development, it is necessary to make effective interaction between the industrial elements of Shandong province and increase the penetration of strategic emerging industries in the traditional industries. In this way, the new technology and traditional industries can be integrated effectively, the production level of traditional industries can be improved, the capital market is constantly improved, and the traditional production can be made. The industry presents a diversified trend of development and promotes the stable development of the economic structure.

(2) The interactive development of industrial structure. At present, the traditional industry in Shandong province is an important guarantee for the social and economic development, and because of the long development time, a lot of experience has been accumulated in the process of development. However, based on the long-term perspective, we must strengthen the strategic layout of the emerging industries and make the new industries the next pillar industry, in order to make the development sustainable. For the adjustment of industrial structure, it is necessary to carry on effective transition and undertake, combine the characteristics of strategic emerging industry and traditional industry, continuously make the strategic emerging industries inherit the traditional industry, and realize the optimization and upgrading of the whole industrial structure.

(3) The interactive development of industrial layout. For regional industrial layout, regional division of labor is usually done from a static perspective, and then regional transfer is realized from a dynamic perspective. For strategic emerging industries, most of them rely on resources and technology for their own development, which will focus on the development factors of talent training, so it will be concentrated in more specific areas. Taking Shandong as an example, the development of new technology industry in Ji'nan and other areas has a certain advantage compared with other areas, because the technical talent is more concentrated, so it can provide powerful support to the new industry. In cities such as Qingdao, Linyi and Rizhao, the main development of tourism, steel and manufacturing is directly related to its own geographical location and energy characteristics. Therefore, in the interactive development of strategic emerging industries and traditional industries, it is necessary to carry out reasonable industrial layout, realize the rational division of labor and enhance industrial interaction between regions, so as to make the overall economic development more stable.

\section{The Development of Strategic Emerging Industries and Traditional Industries in Shandong}

\subsection{Optimization transformation of traditional manufacturing industry}

The traditional manufacturing industry in Shandong is optimizing the transformation. They have applied more new technology in the traditional industry, realized the technological breakthrough and the innovation on the product. Taking the tire manufacturing as an example, Linglong tires, through the use of advanced technology, have made great breakthroughs in the process and materials, and are the only designated suppliers of the red flag guests. Manufacturing industry is the same. Ji'nan's two machine tool plant, its CNC machine has been adopted by Ford in the United States, sales increased by more than $20 \%$. From the above example, we can see that at present, the equipment manufacturing industry in Shandong is making great efforts towards high end and precision. They are not relying on the traditional labor intensive production, and more is the production of high-tech products. This shows that in the economic development of Shandong Province, the traditional manufacturing industry is more cited. Entering the new industry and achieving technological integration is very important for the stability and long-term development of Shandong's economic structure.

\subsection{The rapid development of new industries}

Shandong province is developing the Internet industry vigorously, and teaching internet application in industrial production. For example, Haier group applied the Internet to the entire 
production line when manufacturing air-conditioning, and achieved 4 of the industry. At this time, the enterprise makes the air conditioning gradually change for the user to make air conditioning, so the whole production is more close to the actual demand of the society, and can provide people with more personalized clothes.

\section{The Strategies of Mutual Development between Strategic Emerging Industries and Traditional Industries in Shandong}

The strategic emerging industries and traditional industries are the supporting points of the current economic development. They should be effectively integrated. On the one hand, the traditional industries are optimized and upgraded, on the other hand, to support the strategic emerging industries, it is best to interact together to enhance the permeability of the two, so that the region can effectively promote the region. The economic development of sex.

\subsection{Strengthen government guidance and market regulation}

In the process of developing the strategic emerging industries and traditional industries, we must make effective use of government guidance and market regulation. The market adjustment can be used to optimize the resources reasonably, guide the market through the market supply and demand relationship, promote the innovation of various kinds of science and technology, and make the development of strategic emerging industries strong support. The government guidance is more based on the whole, through the analysis of the actual needs of the region, and then targeted guidance and planning the development of the industry. At the same time, some new strategic industries can also be supported and guided by the policy, which can provide a good social environment for the development of the whole industry, make the competition in the enterprise in a virtuous circle, and then promote the economic development effectively. For Shandong, the government is not enough to support the strategic emerging industries. In the follow-up development, we need to refine the policy and guide and standardize the market continuously.

\subsection{Technology innovation and technology introduction}

The development of traditional industries needs technological innovation and introduction, especially in strategic emerging industries. In the process of development, Shandong must focus on enterprises, constantly deepen technological innovation, and create a platform for industrial innovation. In view of the actual situation in Shandong, we can integrate the universities, enterprises, government and all kinds of research institutes in the process of technological innovation, make clear the demand of industrial technology and strengthen the support of technology tackling, so that the ability of independent innovation can be improved effectively and the maximum of scientific research results can be transformed into economy. The driving force of development provides strong support for the development of various industries.

In the process of independent technological innovation, we should continue to quote new technologies so that we can keep the pace with the times and make effective supplements to their own technology. At present, western countries have done more meticulous in industrial technology, which is an important way for us to learn from and learn from. In the introduction of technology, we must combine its own actual situation, strive to realize the localization of technology, promote the integration of the international technology industry and the Shandong technology industry, which will provide strong support for the economic development of the whole province of Shandong.

\subsection{Overall promotion and key breakthroughs}

In the interactive development of strategic emerging technology industries and traditional industries, we need to plan on the basis of overall planning, and focus on technological breakthroughs. First of all, we should concentrate our scientific and technological resources on high and new technology enterprises, focus on breaking through the bottleneck of current development, and grasp the rhythm of economic development. Through this phase, we can create a series of leading 
enterprises, which can play a normative role for the whole market. At the same time, it can also play the role of guidance and radiation, let the whole industry continue to extend and expand, and form a new industry group.

The overall promotion is more to integrate strategic emerging industries into traditional industries, and the development of many traditional industries has been in trouble, and they need the development direction of technology support. In view of this situation, we can optimize and integrate the actual needs of the society. For example, mechanical processing, textile and manufacturing, Internet technology, large data technology, cloud computing technology can be introduced into it, the use of modern technology to optimize it, old equipment also needs to be updated in time, which has a greater role in promoting the core competitiveness of the traditional industry. Only by effectively integrating the development of traditional enterprises and strategic emerging industries can we make long-term planning on the whole and promote the sustainable development of the economy.

\subsection{Cultivate new enterprises and support traditional enterprises}

The current industrial integration in Shandong is in the stage of transformation. The transition period needs strong support from the government. On the one hand, the existing traditional enterprises should be given reasonable support, which is the motive force of the long - term development of the whole Shandong economy; on the other hand, it should be based on the cultivation of new enterprises for a long time, which is the focus of the industrial transition. Relying solely on the market to adjust the industry of Shandong Province, it may lead to the shortage of traditional industries. Therefore, it is necessary for the government to carry out an overall plan, based on a scientific perspective for long-term planning, and cultivate key goals and enterprises. In the process of supporting, we should make individualized plans for the actual situation of the enterprises, break the conventional and traditional restrictions, and take more advanced means to control the economic development of the current Shandong province.

\section{Conclusion}

The interactive development of the strategic emerging industries and traditional industries in Shandong needs to be explored and perfected in the current practice, and the pertinent measures are put forward through summing up and analyzing the problems. At present, the degree of integration of strategic emerging industries and traditional industries is increasing, which needs to be adhered to to enhance the interaction between the two and let one side move the other and achieve common development. Only by doing well the interaction between the traditional industry and the strategic new industry can the economic development conform to the trend of the society, at the same time, the competitiveness and vitality of the industry will be strengthened, and it can provide a powerful development for the leapfrog development of the economy of Shandong province.

\section{References}

[1] Liu Manfeng, Li Xinyao. Measurement verification of the interactive development of China's strategic emerging industries and traditional industries -- Based on the production function perspective [J]. Journal of Jiangxi University of Finance and Economics, 2017 (04): 14-23+134.

[2] Wang Shurong. Analysis of the path of interaction between traditional industry and strategic new industry in Dalian Jin Pu new area [J]. Journal of Hubei University of Economics (HUMANITIES AND SOCIAL SCIENCE EDITION), 2016,13 (06): 19-20+32.

[3] Liang Jun, Zhao Fangyuan. Regional differences and changes in the interactive development of emerging industries and traditional industries -- An Empirical Study Based on grey relational model, [J]. commentary, 2014,5 (06): 5-16.

[4] Dong Shu Gong. Synergy and integration: effective path for the interactive development of strategic emerging industries and traditional industries [J]. modern economic discussion, 2013 (02): 
71-75.

[5] Chen Aixue. An analysis of the interactive development between traditional industries and strategic emerging industries: Based on the study of Inner Mongolia's [J]. industrial technology economy, 2012,31 (09): 112-116.

[6] Xiong Yongqing, Li Shicai. The benign interactive development of strategic emerging industries and traditional industries -- Based on the analysis and consideration of the status quo of China's industrial development, [J]. technology progress and countermeasures, 2011,28 (05): 54-58. 